\section{Sustainable solid waste management}

J. W. C. Wong, R. Y. Surampalli, T. C. Zhang, R. D. Tyagi and A. Selvam (eds). American Society of Chemical Engineers, Reston, VA, USA, 2016, ISBN 978-0-7844-1410-1, US\$170, 750 pp.

Sustainable Solid Waste Management, is edited by a team of five experienced professionals with an enviable publication record across the breadth of academic and industrial fields of environmental engineering. This widely referenced, fully indexed, 728-page textbook provides an all-encompassing pathway from introduction to advanced knowledge across the waste management sector. Accessible explanations and key principles make up a logical pattern of 22 chapters of technical, social and legal themes. Sponsored by the Environmental and Water Resources Institute of the American Society of Civil Engineers this is a significant undertaking to address a subject whose scope covers the disposal of all resources from manufacture, use and the final residue of materials within our commercial, industrial and municipal lives.

Working with many expert authors for each chapter, typically between two and five, the editorial team provided a structure to address a logical sequence of waste management questions. Editorial guidance is evident in balancing introductions for each area with technical details and contemporary developments. This informative approach helps the reader understand the solid waste management world while having the choice to read the book in sequence like a novel or as a reference text.

Solid waste management addresses all materials that are disposed of other than those transported through the wastewater system. Despite the unlimited scope, the management process seeks to recover value from these resources, either by product or material reuse, as an amendment to soils, as a source of energy or in a prioritised sequence of these approaches. Disposal of the non-economic residue then becomes the priority. This book addresses this challenging scope. The content covers this sequence which is also reflected in the structure of the book. Knowledge of environmental priorities that make up the concept of sustainability are set out in the introduction in chapter 1. Material characteristics, methods of material handling and storage, then waste prevention and recycling are covered in chapters 2 to 5 . Communities play an important role in the early-stage sequence of reducing waste, collecting and segregating materials, and chapter 6 introduces the main set of issues that influence public policy. Chapters 7 to 14 then explain the rationale and principles for a range of thermal, biological, physical and chemical methods that define current waste-treatment processes as well as some in early-stage development. High-hazard and large-volume wastes are explained in two chapters, 16 and 17, respectively, where healthcare waste, a commonly overlooked sector, and construction and demolition (C\&D) wastes are discussed. $C \& D$ is receiving increasing international attention from recognition of the large-scale loss of materials. Management of final residues in the form of ash from processing and landfill design, operation and aftercare then make up chapters 17 to 20 . Importantly, the importance of the legal framework for defining wastes and thus the control of materials is explained in chapter 21. The majority of materials become waste when they are no longer economically viable to use again. Investment in capital and operational costs, determine the feasibility of waste collection and separation to recover materials. When these cumulative costs outweigh the value of materials then material becomes waste. It is then a task for society to manage the process of aggregating materials and prioritising investment to minimise energy use while maximising value. While legislation requires developed societies to recover and manage wastes, the decisions about how to do this need to be informed by balance energy inputs with polluting outputs. The final chapter focuses on life-cycle analysis as the basis for informing these decisions to prioritise process selection.

In achieving a balance between structure and detail, this book helps the reader understand scope, priorities and process technologies at the same time. The challenge for an editor is what to leave out and there are few exceptions here. Sensible boundaries are drawn where wide categories such as hazardous materials are dealt with as a set of principles rather than specifics. While this leaves some readers with the most enquiring minds frustrated, it allows the majority of readers use of a book they can carry. As international focus on waste increases, this text provides a valuable introduction to the issues, technologies and priorities across the field of solid waste management.

Phil Longhurst 